EMBRYARIDDLE
Aeronautical University

SCHOLARLY COMMONS
International Journal of Aviation, Aeronautics, and Aerospace

$11-3-2016$

\title{
Applying the Technology Acceptance Model to Understand Aviation Students' Perceptions toward Augmented Reality Maintenance Training Instruction
}

\author{
Yu Wang \\ Purdue University, wangyu@purdue.edu \\ Amadou Anne \\ aanne@purdue.edu \\ Tim Ropp \\ Purdue University, tropp@purdue.edu
}

Follow this and additional works at: https://commons.erau.edu/ijaaa

Part of the Aviation and Space Education Commons, Instructional Media Design Commons, and the Maintenance Technology Commons

\section{Scholarly Commons Citation}

Wang, Y., Anne, A., \& Ropp, T. (2016). Applying the Technology Acceptance Model to Understand Aviation Students' Perceptions toward Augmented Reality Maintenance Training Instruction. International Journal of Aviation, Aeronautics, and Aerospace, 3(4). https://doi.org/10.15394/ijaaa.2016.1144

This Article is brought to you for free and open access by the Journals at Scholarly Commons. It has been accepted for inclusion in International Journal of Aviation, Aeronautics, and Aerospace by an authorized administrator of Scholarly Commons. For more information, please contact commons@erau.edu. 
Augmented Reality (AR) Technology has been widely utilized in many areas within the fields of education, research, and commerce. In recent years, the technology has been applied to the design, manufacturing, and maintenance of aircraft, as well as aviation personnel training. More specifically, AR maintenance instructions have been introduced to aviation maintenance training. These instructions include more interactive content, friendlier and more efficient user interfaces, enhanced visualizations and real-time data when compared to traditional paper or computer-based instructions. Hence, AR instructions have shown the potential to improve the quality and delivery of maintenance training in aviation (Macchiarella \& Vincenzi, 2004).

Although research has been carried out to demonstrate the features and functions that AR-based maintenance instructions can provide, little research has been done to identify users' relative perception of the merits and drawbacks of AR maintenance instructions. Regardless of the actual benefits provided by AR maintenance instructions, their successful implementation within the maintenance training environment is rooted in the acceptance level of its potential users. Therefore, this study specifically targeted the perceptions of aviation maintenance students toward the use of AR maintenance instructions in aviation maintenance training operations. More importantly, the study used the Technology Acceptance Model (TAM) to explain and predict relationships among ease of use, usefulness, attitude, and intention regarding the implementation and use of AR maintenance training instructions.

\section{Literature Review}

\section{Introduction to AR}

$\mathrm{AR}$ is defined as the technology that overlays computer-generated data on top of a real image or view through a digital piece of hardware. AR consists of the display of information (text, images, videos, and interactive content) that augments a scene that is actively captured by a camera (De Crescenzio et al. 2011). The type of data displayed can vary from simple text lines to videos and even interactive 3D models. The hardware required to access and visualize the AR content consists of a camera, a display, and a data processing unit equipped with the proper software to achieve the task. This equipment is currently integrated - albeit at different quality and performance levels - in personal computers, cell phones, tablets and certain head-mounted devices (HMD) among others. AR has been used - or at least experimented with - in many domains, such as marketing, entertainment, as well as in medical and technical fields (Hincapie, Caponio, Rios, \& Medivil, 2011). 
AR has been the subject of much research and development over the past decade. This has led to the technology being tested and used in many sectors. As Ong and Nee illustrate (Nee, Ong, Chryssolouris, \& Mourtzis, 2012; Ong \& Nee, 2008), AR is being widely used in marketing and advertisement and has been successfully demonstrated and used in medical, military, entertainment, maintenance and manufacturing fields.

\section{Current Aviation Maintenance and Training}

Over the past few decades, the volume of air travel has considerably increased, and aircraft have become increasingly modern, complex and inclusive of numerous and diverse auxiliary systems. Thus, the concepts and processes associated with manufacturing, maintenance, and training - of aviation professionals - have also significantly increased in breadth and complexity. In turn, this has led to a large volume of reference material being necessary to perform tasks in the aforementioned fields. As highlighted in previous publications (Nee et al., 2012), manufacturing, for instance, has become much more complex and demanding and in virtually all cases requires the exchange of information in real time between different units of production.

Traditional methods of information delivery and exchange - specifically standard printed or digital texts and manuals - are still very widely used in the industry. Although they are cost-effective and well implanted throughout, they have several disadvantages when considered in the modern aviation world. Indeed, if one considers, for instance, the recurring need to update information (through Advisory Circulars, Airworthiness Directives or manufacturer publications), it is clear that traditional methods -consisting of end-user additions to publications for instance incur undeniable inefficiencies and thus potential safety risks.

Also, workers in the field using traditional methods of information delivery typically experience many issues when performing given tasks. Indeed, instructions are usually detached from the equipment that the technicians are performing work upon - from a few inches away to potentially out of physical range -, which leads to the need to constantly switch focus between their instructions and work platform (Ong \& Nee, 2008). This causes a high loss of time and productivity, as well as a higher potential for errors and injuries or damage.

In addition, as Hincapie et al. (2011) described, the information in traditional methods can be challenging to locate and extract. Indeed, workers and students - especially if inexperienced - can be led to frustration, poor performance, 
and potentially costly mistakes when trying to find information in traditional texts and manuals.

Overall, in the aviation industry, data related to performing training or field technical operations is delivered primarily in one of two ways: through paper-based instructions and manuals or in digital format (Wang \& Steven, 2014). The digital data is either similar in content and format to the paper-based instructions or may contain enhanced visuals and some level of interactivity. Each of these methods of data delivery has advantages, but also severe drawbacks, which lead to technical documentation being considered the primary human factors challenge in aviation maintenance. In fact, 45 to $60 \%$ of safety incidents were procedure related or involved technical documentation. Thus, there is a clear need for the implementation of new ways to deliver information to technicians for training and in the field that will facilitate retention of knowledge and execution of the tasks while decreasing errors and thereby diminishing safety hazards for the worker and ultimately the users of the aircraft (FAA, 2012).

\section{Potential of AR Aviation Maintenance and Training}

There have been many research projects involving $A R$ in aviation maintenance operations and training. Many of these have focused on comparing augmented-reality methods of information delivery to currently common ones such as text, images, and video.

In aviation training and education, $\mathrm{AR}$ has been proven as a more effective learning tool than text or video-based methods (Macchiarella \& Vincenzi, 2004), and could for instance help reduce training time and costs in maintenance, which typically amount to about 2000 hours (Hincapie et al., 2011). One project conducted by Ong, Yuan, and Nee, has demonstrated that AR is more effective than other forms of instructions, as it reduces errors and makes tasks easier (Ong, Yuan, \& Nee, 2008). Another study by Macchiarella and Vincenzi (2004), which was designed to compare AR to video and text-based learning methods, compared shortterm and long-term recollection of a topic in an aviation setting. The results obtained showed that AR produced significantly better long-term retention of information and thus was a better learning platform.

Beyond some of the efficiency improvements discussed above, AR can provide multiple new ways to enhance information delivery in aviation. In fact, as Kesim and Ozarslan (2012) noted, it allows for much better visualization and manipulation of objects and figures displayed on-screen. In addition, information is displayed in the user's field of view, which gives them the ability to assimilate it 
better and concentrate more on the tasks to perform (Ong \& Nee, 2008). The flexibility of AR also makes it applicable to several different types of processes and the AR-enhanced information is virtually always physically smaller (in weight and volume) than comparable information in print or other computer-based formats (Hincapie et al., 2011; Ong \& Nee, 2008). This translates into more mobility, but also less time wasted accessing and retrieving information since the right information can be shown when and where it is needed (Ong \& Nee, 2008).

In practical tasks then, AR provides the benefits of added efficiency, safety and reduced waste of resources. More recent research of graphics based air vehicle maintenance work instructions with user controlled augmenting data presentations (animated 3D models, interactive troubleshooting locations) during task-dense processes has shown that properly applied visualization and component presentation of technical or systems, when provided directly at the task location itself can improve efficiency and accuracy while resulting in reduction of rework due to missed or out of sequence steps (Hartman \& Ropp, 2013; Kim et al., 2010). Although the literature has shown great features that AR-enhanced information can provide, research has yet to identify the users' perceptions of this new style of maintenance instructions. Given the fact that aviation maintenance students will undoubtedly be the future primary users of such AR-based instructions, this study focused on their reaction to the technology. To evaluate this, the Technology Acceptance Model was used.

\section{Technology Acceptance Model}

The Technology Acceptance Model (TAM) was developed by Davis (1986) by the Theory of Reasoned Action (TRA). TRA posits that one's behavior is directly influenced by behavioral intention that is a function of his/her attitudes and subjective norms toward the behavior (Davis, 1989; Masrom, 2007). Figure 1 depicts the Theory of Reasoned Action.

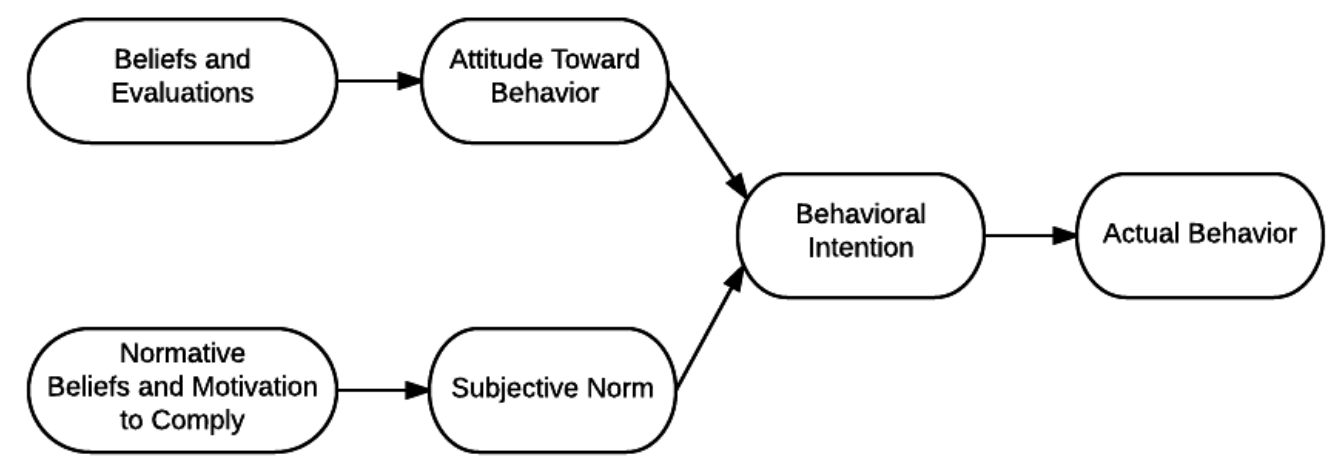

Figure 1. Theory of Reasoned Action 
TAM aims to understand and explain user acceptance of a new technology (Davis, 1989). The model has been widely utilized by different research fields to understand and predict user behaviors. It provides a theoretical model to assist in explaining the relationships among external variables, perceived usefulness, perceived ease of use, attitude, intention to use, and actual use (Davis, 1989; Legris, Ingham, \& Collerette, 2004; Park, 2009). TAM proposes that external variables, perceived usefulness, perceived ease of use, attitudes, and intentions to use directly and indirectly affect a user's actual use of a technology system. Additionally, one's actual use and intentions are influenced by external variables via the mediators and predictors: perceived usefulness and ease of use (Davis, 1989; Masrom, 2007). Perceived usefulness refers to "the degree to which an individual believes that using a particular system would enhance his or her job performance" (Davis, 1989, p. 320). By contrast, perceived ease of use refers to ""the degree to which a person believes that using a particular system would be free of effort" (Davis, 1989, p. 320). Figure 2 presents the original TAM (Davis, 1989).

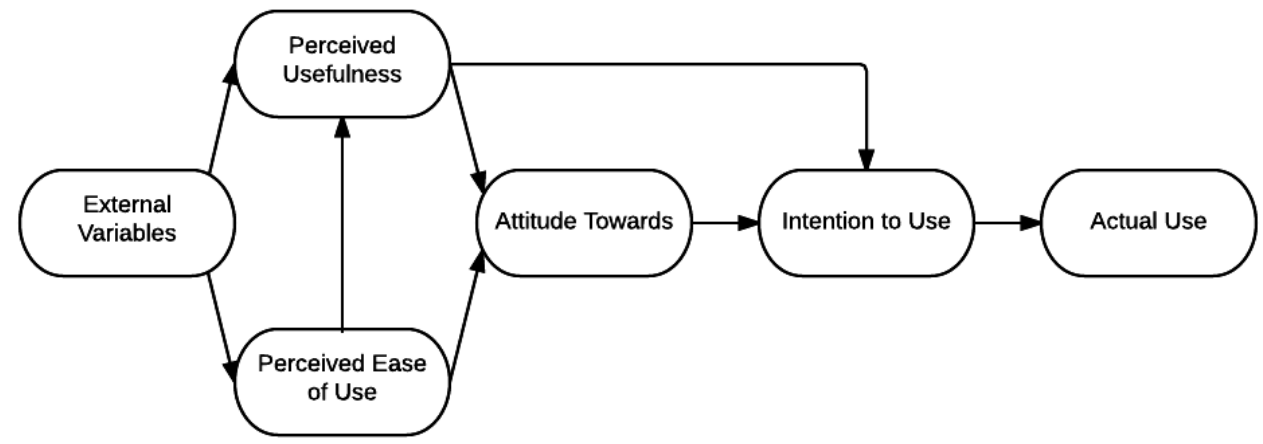

Figure 2. Original Technology Acceptance Model (Davis, 1989)

Masrom (2007) proposes a simplified TAM that excludes actual use and external variables. The researchers of this study utilized the simplified model to explain and predict the acceptance of aviation students using AR maintenance instructions. The following hypotheses were proposed by the researchers of this research study based on the simplified TAM (shown in Figure 3):

H1: Perceived ease of use has a significant effect on perceived usefulness

H2: Perceived ease of use has a significant effect on attitude towards using H3: Perceived usefulness has a significant effect on attitude towards using

H4: Perceived usefulness has a significant effect on intention to use

H5: Attitude towards using has a significant effect on intention to use 


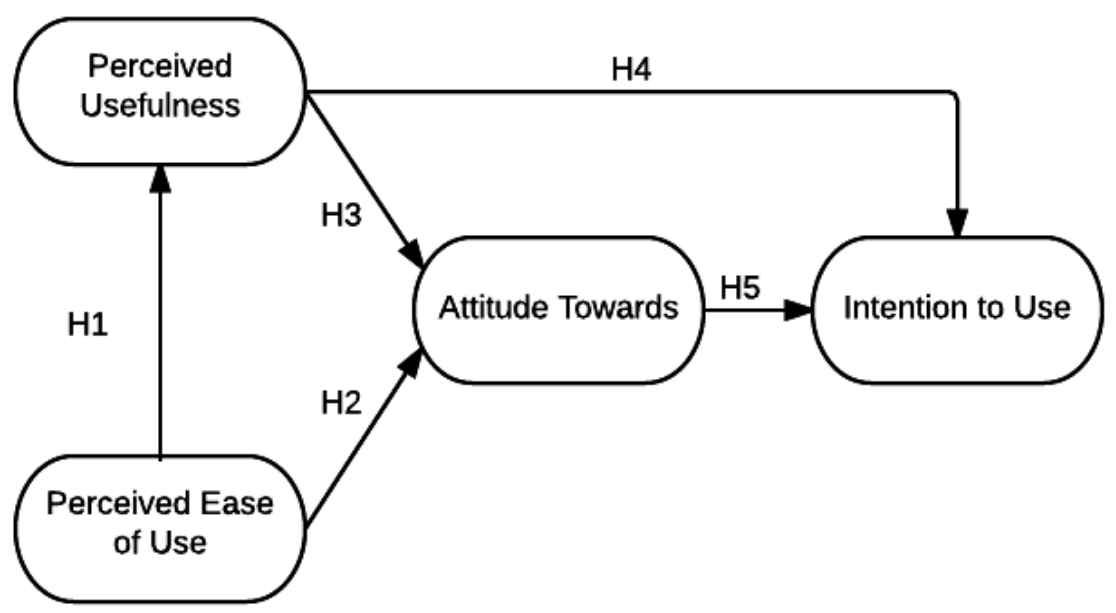

Figure 3. Hypotheses based on the simplified Technology Acceptance Model

\section{Methodology}

\section{Participants}

Forty-one participants who were undergraduate aviation students at a Midwestern university took part in this research study. All participants had at least two years of theoretical and practical experience conducting maintenance of aircraft systems in an educational setting. The practical task that the study was based on (F109 engine fan disassembly) was one that all subjects had previously had exposure to through paper-based maintenance instructions in a maintenance lab. Participants were contacted by the researchers in person and volunteered to participate in this study. Table 1 depicts the demographic information of the participants in this study.

\section{Data collection}

The data collection of this study consisted of two phases. During Phase one, the researchers demonstrated a set of AR maintenance instructions to participants. The AR demonstration was used to show the fan removal process of the F109 engine and to explain the features and usage of the AR software. The purpose of the demonstration was to allow participants to fully understand how to operate the $\mathrm{AR}$ instruction. 
Table 1

Demographic information of participants

\begin{tabular}{lrr}
\hline Items & Number $(\mathrm{N})$ & Percent $(\%)$ \\
\hline Gender & 37 & 90.24 \\
Male & 4 & 9.76 \\
Female & & \\
& 12 & \\
School Year & 21 & 29.27 \\
Junior & 8 & 51.22 \\
Senior & & 19.51 \\
Did not report & 18 & \\
& 21 & 43.90 \\
Age & 2 & 51.22 \\
18-21 & & 4.88 \\
22-24 & 41 & 100.0 \\
25 or older & & \\
Total & & \\
\hline
\end{tabular}

During the second phase, participants were given a chance to use and interact with the AR instructions individually. They were then requested to complete a paper survey. The survey questionnaire of this study was adapted from Masrom's study (2007) and was intended to examine TAM for the implementation and use of AR instructions in aviation training operations. The survey included four demographic questions, sixteen 7-point Likert-type questions, and one open-ended question. The format of the 7-point Likert-type item used by the researchers was: 1-Strongly disagree, 2-Disagree, 3-Somewhat disagree, 4-Neutral, 5-Somewhat agree, 6-Agree, and 7-Strongly agree. The open-ended question aimed to obtain participants' comments on the future implementation of AR instructions in an aviation training setting.

\section{Data analysis}

The researchers analyzed the data obtained from the survey by using the SPSS statistical package. Factor analysis was used to test the construct validity of the survey questionnaire. Cronbach's Alpha reliability analysis was used to examine the internal consistency of survey items. Additionally, linear regression analysis was used to identify relationships among the variables: ease of use, usefulness, attitude, and intention to use AR instructions. The means of variables were used for regression analyses. 


\section{Results}

\section{Reliability analysis}

To evaluate internal consistency and reliability of variables in this study, a Cronbach's alpha reliability analysis was conducted. A Cronbach's alpha value of greater than 0.7 is considered an acceptable reliability level (Tavakol \& Dennick, 2011; Santos, 1999). All Cronbach's alpha values in this study were above 0.7, which demonstrated a high internal consistency and reliability. Table 2 shows the Cronbach's Alpha values for the internal reliability testing.

Table 2

Cronbach's Alpha Values

\begin{tabular}{cc}
\hline Item & Cronbach's $\alpha$ \\
\hline Perceived ease of use & .738 \\
Attitude towards using & .857 \\
Perceived usefulness & .907 \\
Intention to use & .885 \\
\hline
\end{tabular}

\section{Factor analysis}

Factor analysis was utilized to examine the construct validity of four factors: perceived ease of use, attitude towards using the technology, perceived usefulness, and intention to use. Four items were included in the survey questionnaire to measure each factor. A factor analysis score greater than 0.6 is considered a good level of survey validity (Chesney, 2006). All of the factor analysis scores in this survey were greater than 0.6 , which showed a good validity and reliability of the survey. Table 3 displays the results of the factor analysis.

\section{Regression results}

A separate linear regression analysis was conducted to test Hypothesis 1 (H1), in which perceived ease of use was used as an independent variable, and perceived usefulness was used as dependent variable. As shown in Table 4, Hypothesis 1 (H1) failed to be rejected with $\beta=.677$ and $p<.001$. Therefore, perceived ease of use has a significant effect on perceived usefulness.

Hypothesis $2(\mathrm{H} 2)$ and Hypothesis $3(\mathrm{H} 3)$ were tested by using linear regression analyses (the regression results indicated in Table 5). The regression results indicated that both perceived ease of use and perceived usefulness have a 
significant effect on attitude towards using with $\mathrm{p}<.001$. Therefore, both Hypotheses 2 and 3 (H2 and $\mathrm{H} 3$ ) failed to be rejected.

Table 3

Factor analysis results

\begin{tabular}{ccccc}
\hline Item & 1 & 2 & 3 & 4 \\
\hline EOU 1 & 0.69 & & & \\
EOU 2 & 0.88 & & \\
EOU 3 & 0.60 & & \\
EOU 4 & 0.79 & &
\end{tabular}

$\begin{array}{ll}\text { PU 1 } & 0.87 \\ \text { PU 2 } & 0.90 \\ \text { PU 3 } & 0.92 \\ \text { PU 4 } & 0.85\end{array}$

$\begin{array}{ll}\text { ATT } 1 & 0.86 \\ \text { ATT } 2 & 0.87 \\ \text { ATT } 3 & 0.81 \\ \text { ATT } 4 & 0.85\end{array}$

INT $1 \quad 0.86$

INT $2 \quad 0.84$

INT $3 \quad 0.88$

INT $4 \quad 0.88$

Note. EOU $=$ Perceived ease of use; PU = Perceived usefulness; ATT = Attitude toward using; INT

$=$ Intention to use

Table 4

Linear regression result for hypothesis 1

\begin{tabular}{lllll}
\hline & $\beta$ & $p$ & $t$ & $R^{2}$ \\
\hline Perceived ease of use & .677 & $<.001$ & 5.581 & .458 \\
\hline
\end{tabular}

Table 5

Linear regression results for Hypotheses 2 and Hypothesis 3

\begin{tabular}{lllll}
\hline & $\beta$ & $p$ & $t$ & $R^{2}$ \\
\hline Perceived ease of use & .594 & $<.001$ & 4.667 & .353 \\
Perceived Usefulness & .850 & $<.001$ & 10.210 & .723 \\
\hline
\end{tabular}


Similarly, Hypothesis 4 (H4) and Hypothesis 5 (H5) were tested by linear regression analyses with perceived usefulness and attitude as independent variables, and intention to use as a dependent variable. The regression results indicated both perceived usefulness and attitude towards using have a significant effect on intention to use. Therefore, both Hypothesis 4 (H4) and Hypothesis 5 (H5) failed to be rejected.

Table 6

Linear regression results for Hypothesis 4 and Hypothesis 5

\begin{tabular}{lllll}
\hline & $\beta$ & $p$ & $t$ & $R^{2}$ \\
\hline Perceived Usefulness & .643 & $<.001$ & 5.310 & .413 \\
Attitude Towards & .601 & $<.001$ & 4.762 & .362 \\
using & & & & \\
\hline
\end{tabular}

\section{Discussion}

Across all participants of this research study, there were not any indications of negative attitudes regarding the development, use, and implementation of AR maintenance training materials. Survey respondents expressed overall support for incorporating AR-based maintenance instructions into maintenance training operations. As one survey respondent stated: "The use of Augmented Reality would vastly improve the quality of learning in all AET classes."

The applicability of TAM to aviation student acceptance of AR technology was fully supported. According to survey responses, participants acknowledged and appreciated the advantages that AR instructions provide regarding ease of use and usefulness. Both ease of use and usefulness had a significant effect on aviation students' attitude toward using AR instructions. Also, students' intention to use AR technology was indirectly and directly affected by ease of use and usefulness respectively. Therefore, improving ease of use and usefulness may play a very important role in determining a successful implementation of AR training material. This confirms that two of AR designers and developers' key emphases should be on usefulness and ease of use. Furthermore, the survey results showed that aviation students' attitude had an impact on their intention to use an AR technology. A positive attitude from aviation students should be established to ensure a success of the future AR implementation.

There are some limitations of this research study that must be acknowledged. Due to a limited number of aviation maintenance students at the Midwestern university surveyed, this study had a small sample size, which could restrict this study from coming to a persuasive conclusion, especially from a quantitative 
analysis standpoint. In addition, the research study did not examine the full (original) TAM. Two constructs, actual use, and external variables were not included in the TAM examination. What follows are recommendations for future studies to deal with the limitations.

In future studies, research including a larger group of participants is recommended. Also, future research studies should include other possible AR users, such as aviation maintenance lab instructors who may use AR maintenance training instructions to instruct aviation students to conduct maintenance operations, or maintenance professionals, who would have experience in the domain. Their perceptions and attitudes towards the use of AR instructions would be very helpful in enhancing the future design and development of AR based instructions. Additionally, some experimental studies to compare AR and traditional (paper or digital) maintenance instructions in efficiency and accuracy can be carried out. For example, two groups of aviation students use AR and paper instructions respectively to perform the same maintenance task. Some measurement metrics could be accuracy, overall time, and other comparative respects.

\section{Conclusion}

The purpose of this study was to examine TAM for aviation students' acceptance of AR instructions and to identify perceptions and attitudes of aviation maintenance students about the future utilization of AR maintenance manuals in aviation maintenance training. The findings confirmed that TAM could be a useful theoretical model to help gain a clearer understanding of relationships among usefulness, ease of use, attitude towards using, and intention about the implementation of AR instruments. From an overall view, survey respondents accepted and supported the future use of AR maintenance materials. More importantly, this study was one of the first studies to incorporate TAM in AR implementation of an aviation training setting. The results may lay a foundation for future researchers and AR developers dealing with the AR implementation in the aviation industry. 


\section{References}

Chesney, T. (2006). An acceptance model for useful and fun information systems. Human Technology: An Interdisciplinary Journal on Humans in ICT Environments, 2(2), 225-235. doi:10.17011/ht/urn.2006520

Davis, F. D. (1989). Perceived usefulness, perceived ease of use, and user acceptance of information technology. MIS Quarterly, 13(3), 319-339. doi: $10.2307 / 249008$

De Crescenzio, F., Fantini, M., Persiani, F., Di Stefano, L., Azzari, P., \& Salti, S. (2011). Augmented reality for aircraft maintenance training and operations support. Computer Graphics and Applications, 31(1), 96-

101. doi:10.1109/mcg.2011.4

Federal Aviation Administration. (2012). Technical documentation challenges in aviation maintenance - A proceedings report (FAA Publication No. AM12/16). Washington, DC: Office of Aerospace Medicine.

Hartman, N., \& Ropp, T. (2013). Examining the use of model-based work instructions in the aviation maintenance environment. Proceedings of the 10th International Conference on Product Lifecycle Management, PLM13, 8th - 10th July 2013. Nantes, France.

Hincapie, M., Caponio, A., Rios, H., Mendivil, E.G. (2011). An Introduction to augmented reality with applications in aeronautical maintenance. Proceedings from 13th International Conference on Transparent Optical Networks (ICTON). IEEE, Stockholm.

Kesim, M., Ozarsalan, Y. (2012). Augmented reality in education: current technologies and the potential for education. Procedia - Social and Behavioral Sciences, 47, 297-302. doi:10.1016/j.sbspro.2012.06.654

Kim, S., Woo, I., Maciejewski, R., Ebert, D. S., Ropp, T. D., \& Thomas, K. (2010, July). Evaluating the effectiveness of visualization techniques for schematic diagrams in maintenance tasks. Proceedings of the 7th Symposium on Applied Perception in Graphics and Visualization. Los Angeles, California. Session: displays and visualization (pp. 33-40). ISBN:978-1-4503-0248-7. 
Legris, P., Ingham, J., \& Collerette, P. (2003). Why do people use information technology? A critical review of the technology acceptance model. Information \& Management, 40(3), 191-204. doi:10.1016/s03787206(01)00143-4

Macchiarella, N. D., \& Vincenzi, D. A. (n.d.). Augmented reality in a learning paradigm for flight aerospace maintenance training. The 23rd Digital Avionics Systems Conference (IEEE Cat. No.04CH37576). doi:10.1109/dasc.2004.1391342

Masrom, M. (2007). Technology acceptance model and e-learning. Technology, 21,24 .

Nee, A. Y. C., Ong, S. K., Chryssolouris, G., \& Mourtzis, D. (2012). Augmented reality applications in design and manufacturing. CIRP AnnalsManufacturing Technology, 61(2), 657-679.

Ong, S. K., Yuan, M. L., \& Nee, A. Y. C. (2008). Augmented reality applications in manufacturing: a survey. International journal of production research, 46(10), 2707-2742.

Park, S. Y. (2009). An Analysis of the Technology Acceptance Model in Understanding University Students' Behavioral Intention to Use eLearning. Educational Technology \& Society, 12 (3), 150-162.

Santos, J. R. A. (1999). Cronbach's alpha: A tool for assessing the reliability of scales. Journal of Extension, 37(2), 1-5.

Tavakol, M., \& Dennick, R. (2011). Making sense of Cronbach's alpha. International Journal of Medical Education, 2, 53. doi: 10.5116/ijme.4dfb.8dfd

Wang, Y., \& Leib, S. (2014). Understanding the perceptions of Chinese aviation maintenance technicians related to the implementation and use of 3D aircraft maintenance manuals. Collegiate Aviation Review, 32(2), 66. 